\title{
A conical mandrel tube drawing test designed to assess failure criteria.
}

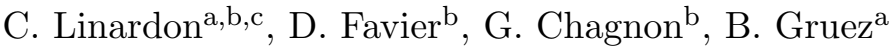 \\ ${ }^{a}$ Minitubes, Zac Technisud, 21 rue Jean Vaujany, BP 2529, 38035 Grenoble Cedex 2, France. \\ ${ }^{b}$ UJF-Grenoble 1/CNRS/TIMC-IMAG, UMR5525, 38041 Grenoble, France. \\ ${ }^{c}$ Université de Grenoble Alpes/CNRS/Lab3SR, BP53, 38041 Grenoble Cedex 9, France.
}

\begin{abstract}
Cold tube drawing is a metal forming process which enables to produce tubes with high dimensional precision. It consists in reducing tube dimensions by pulling it through a die. Tube outer diameter is calibrated by a die and the tube inner diameter and thickness are calibrated by a mandrel. One of the major concern of metal forming industry is the constant improvement of productivity and product quality. In the aim of pushing the process to the limit the question is how far the material can be processed without occurrence of failure. In the present study, a long conical mandrel with a small cone angle was designed in order to carry out drawing tests up to fracture with experimental conditions very close to the industrial process. The FEM of the process was built in order to access the local stress and strain data. A specific emphasis was put on the friction characterisation. For that purpose force measurement during the conical mandrel experiments enabled to characterise a pressure dependent friction coefficient constitutive law by means of an inverse analysis. Finally, eleven failure criteria were selected to study the drawability of cobalt-chromium alloy tubes. The assessment of failure criteria based on damage variables or damage accumulation variables involved their calibration on uniaxial tensile tests. The experimental studies were completed by SEM fractography which enabled to understand the fracture locus and the propagation direction of the fracture.
\end{abstract}

Keywords: Tube Drawing; Metal Forming; Finite element modelling; Fracture; Failure criteria;

\section{Introduction}

There is a growing concern in the metal forming industry to improve the quality of the produced parts while reducing manufacturing time and production costs. Process optimisation requires trials and errors which are time and money consuming. The current development of finite element modelling (FEM) allows to improve the understanding of the process by accessing history of stress and strain distributions in the formed part. Thus, FEM combined with specific designed tests is a tool for process optimisation.

This study focuses on the cold tube drawing process which is widely used to manufacture tubes for biomedical applications (Poncin et al., 2004; Fang et al., 2013; Hanada et al., 2013). Such tubes are required to have precise dimensions and a good surface finish that can not be obtained with the extrusion process. The principle of cold drawing is to reduce tube cross section and wall thickness by pulling a tube through a die. Tube outer diameter is calibrated by the die diameter. In the particular case of mandrel drawing, a rod is inserted inside the tube in order to calibrate the inner diameter. The process is performed at room temperature. The end product is the result of a series of drawing passes in order to progressively reduce inner and outer diameters. Each pass is defined 
in such a way that the tube is plastically deformed and the fracture is prevented. The growing concern of reducing production time and cost requires each pass to be optimized. Thus imposed plastic deformation has to get closer to the fracture limit. Consequently, process optimization involves failure prediction.

In this study a conical mandrel drawing test was designed in order to calibrate and evaluate ductile failure criteria. The interest of such a test is to calibrate criteria for realistic stress and strain states regarding the tube drawing process. It consists in a long conical mandrel designed to perform tube drawing from zero thickness reduction up to a maximum thickness and section reduction leading to fracture. The failure is characterized by means of failure criteria that are computed by FEM.

This paper begins with a presentation of the methods that are generally used for failure studies. The emphasis is put on the interest of failure criteria. Then, eleven failure criteria which are of interest are presented. A second part details the design of the mandrel and the experimental procedure of the drawing on the conical mandrel. Then the presentation of the experimental results are followed by the development of the methodology to compute the failure criteria. This part deals with the FEM of the conical mandrel drawing with a specific emphasis on the contact and friction characterization. Besides, the calibration of the failure criteria and the characterization of the material constitutive behaviour by means of tensile tests is presented. Finally, a comparative study of the predicted section reductions at failure is made relative to experimental observations to evaluate criteria predictability.

\section{Failure prediction}

\subsection{Introduction}

In the literature, there are four reported methods to study ductile fracture: continuous damage mechanics models (Lemaitre, 1985; Chaboche, 1988), porous solid mechanics models (Gurson, 1977; Tvergaard and Needleman, 1984), cohesive models (Barenblatt, 1962) and phenomenological models. The latter do not directly model physical mechanisms of ductile fracture but predict its occurrence. In industrial forming processes the main issue is to predict failure initiation in order to avoid fracture. The point is not to understand failure mechanism but to have an effective failure indicator. As a consequence, the study of crack propagation and the development of mechanical analysis of ductile cracking is not relevant in this study. Moreover, the implementation in FEM of complex physically based models such as continuous damage mechanics models, porous solid mechanics models or cohesive models is computationally much more time expensive than phenomenological models (Zadpoor et al., 2009). Vallellano et al. (2008) and Takuda et al. (1999) found failure criteria to be good competitors compared to physically based models. They used different failure criteria to predict fracture limits of aluminum 2024-T3 and found the same limits as Lee et al. (1997) and Tang et al. (1999) who used a continuum ductile failure criterion. For these reasons, the emphasis of this study is put on finding criteria for predicting fracture loci and deformation levels at the onset of fracture.

Historically, several failure criteria have been established. They describe the failure in terms of mechanical variables such as stress, strain or mechanical work. In all models presented in this work failure criteria are based on functions which depend on these variables. If these functions reach a critical value, failure is expected. There are two simple models for failure prediction. The first one is to consider that failure occurs when a function of the current stress tensor reaches a critical 
value. The second model is to consider a function of current strain tensor. Both of these models are based on instantaneous damage variable $D$. Their general expressions are the following:

$$
D=f(\underline{\underline{\sigma}}) \text { or } D=f\left(\underline{\underline{\epsilon}}^{p}\right)
$$

where $\underline{\underline{\sigma}}$ and $\underline{\epsilon}^{p}$ are the current Cauchy stress and the plastic strain tensors respectively.

Additionally, there are more complex failure criteria which consider mechanical work. These criteria take into account the stress and strain history. They are based on a damage accumulation variable $D$ whose general expression is detailed below:

$$
D=\int_{0}^{\bar{\epsilon}_{p}} f(\underline{\underline{\sigma}}) d \bar{\epsilon}_{p}
$$

with $d \bar{\epsilon}_{p}$ the equivalent plastic strain increment and $\bar{\epsilon}_{p}$ the current equivalent plastic strain.

Freudenthal (1950) was the first to establish a failure criterion introducing the work of plastic deformation. Cockcroft and Latham (1968) successively suggested that the largest principal stress was more likely to cause fracture and they established a failure criterion based on the highest tensile stress. Brozzo et al. (1972) introduced the level of hydrostatic stress in a new failure criterion in accordance with the study of Bridgman (1952) who showed that imposing hydrostatic pressures could contain the growth of cavities and improve formability. Their conclusions were reinforced recently by $\mathrm{Wu}$ et al. (2009). McClintock (1968), Rice and Tracey (1969) and Oyane et al. (1980) established other failure criteria according to the void growth model and the theory of porous media.

In a general way, the onset of failure is predicted when the ratio of the damage variable (1) or the damage accumulation variable (2) to a limit value reaches 1 :

$$
\frac{D}{D^{\text {crit }}} \geq 1
$$

The critical value $D^{\text {crit }}$ for each criterion is calibrated on mechanical tests like tensile tests or upsetting tests for example.

\subsection{Presentation of eleven failure criteria}

Many researchers have worked on failure criteria and they have suggested different phenomenological expressions of the instantaneous damage or damage accumulation variables. Among all the failure criteria available a limited number of criteria is selected for the purpose of this study. Only criteria that can be calibrated on a single experimental test (i.e. uniaxial tensile test) are chosen. Thus, eleven failure criteria are considered. They are listed in table 1 . In the table $D_{i}$ $(i=1 \ldots 11)$ are the damage variable or damage accumulation variable, $\sigma_{j}\left(\sigma_{1}>\sigma_{2}>\sigma_{3}\right)$ are the three principal stresses, $\tau_{\max }$ is the maximum shear stress, $\bar{\sigma}$ is the Mises equivalent stress and $\sigma_{m}$ is the hydrostatic stress.

\section{The conical mandrel tube drawing test}

The first method to determine tube drawing limit is to perform a series of drawing tests with several mandrels of different diameters. The drawing limit is reached when the use of a mandrel 


\begin{tabular}{clll}
\hline Type & Abbreviation & Criterion & Damage or damage accumulation variable \\
\hline 1 & STRN & Equivalent strain & $D_{1}=\bar{\epsilon}$ \\
\hline 1 & MSS & Maximum shear stress & $D_{2}=\tau_{m a x}=\frac{\sigma_{1}-\sigma_{3}}{2}$ \\
\hline 1 & SHAB & Vujovic and Shabaic $(1986)$ & $D_{3}=\frac{3 \sigma_{m}}{\bar{\sigma}}$ \\
\hline 2 & FREU & Freudenthal (1950) & $D_{4}=\int_{0}^{\bar{\epsilon}_{p}} \bar{\sigma} d \bar{\epsilon}_{p}$ \\
\hline 2 & COCK & Cockcroft and Latham $(1968)$ & $D_{5}=\int_{0}^{\bar{\epsilon}_{p}} \max \left(0, \sigma_{1}\right) d \bar{\epsilon}_{p}$ \\
\hline 2 & RICE & Rice and Tracey (1969) & $D_{6}=\int_{0}^{\bar{\epsilon}_{p}} \exp \left(\frac{3 \sigma_{m}}{2 \bar{\sigma}}\right) d \bar{\epsilon}_{p}$ \\
\hline 2 & BROZ & Brozzo et al. $(1972)$ & $D_{7}=\int_{0}^{\bar{\epsilon}_{p}} \frac{2 \sigma_{1}}{3\left(\sigma_{1}-\sigma_{m}\right)} d \bar{\epsilon}_{p}$ \\
\hline 2 & ARGO & Argon et al. $(1975)$ & $D_{8}=\int_{0}^{\bar{\epsilon}_{p}}\left(\sigma_{m}+\bar{\sigma}\right) d \bar{\epsilon}_{p}$ \\
\hline 2 & OH & Oh et al. $(1976)$ & $D_{9}=\int_{0}^{\bar{\epsilon}_{p}} \frac{\sigma_{1}}{\bar{\sigma}} d \bar{\epsilon}_{p}$ \\
\hline 2 & AYAD & Ayada et al. $(1984)$ & $D_{10}=\int_{0}^{\bar{\epsilon}_{p}} \frac{\sigma_{m}}{\bar{\sigma}} d \bar{\epsilon}_{p}$ \\
\hline 2 & TREN & Tresca energy & $D_{11}=\int_{0}^{\bar{\epsilon}_{p}} \frac{\left(\sigma_{1}-\sigma_{3}\right)}{2} d \bar{\epsilon}_{p}$ \\
\hline
\end{tabular}

Table 1: Details of the selected fracture criteria

makes the drawing impossible. This approach has mainly two drawbacks: it is time consuming due to the number of necessary experiments and the transition between feasible and non-feasible drawing pass is not accurately determined. The process limit can only be approached with an accuracy depending on the diameter range of used mandrels. A conical mandrel tube drawing experiment was created to fill in the disadvantages of the previously presented method.

\subsection{Description of the conical mandrel tube drawing test}

The originality of this test relies on the design of the mandrel which was created to combine three drawing tests in a single one. The geometry of the mandrel is presented in figure 1.

Part (1) of the mandrel is a cylindrical section of constant small diameter enabling a step of hollow sinking. Part (2) of the mandrel is a cylindrical section of constant diameter such as, for a given die and initial tube dimensions, outer and inner tube diameters are reduced but wall thickness is unchanged. Part (3) of the mandrel consists of a conical part with a continuously increasing section. On the last part of the mandrel, drawing takes place with a progressively increasing mandrel diameter to explore a wide range of thickness reduction. The test starts from zero thickness reduction and ends up at failure with the corresponding thickness and section reductions. Thus, using a single mandrel the section and thickness reductions to fracture are known with high accuracy.

The initial tube length was $1000 \mathrm{~mm}$ with an outer diameter of $13.11 \mathrm{~mm}$ and a wall thickness of $1.3 \mathrm{~mm}$. The die has a diameter of $11.48 \mathrm{~mm}$. Nominal mandrel dimensions with the corresponding expected section and thickness reductions are detailed in table 2 .

In a first series of tests a die with a semi-cone angle of $\alpha=13.12^{\circ}$ was used. A second series of drawing tests was performed with die semi-cone angles of $\alpha=5^{\circ}, 16^{\circ}$ and $20^{\circ}$. During the drawing test, the mandrel displacement was measured and the position of the mandrel relative to the die is known. Thus, at any time, the imposed outer diameter and wall thickness reductions are known. The drawing force $\left(F_{\text {Drawing }}\right)$ was recorded during the test by the use of a load cell 


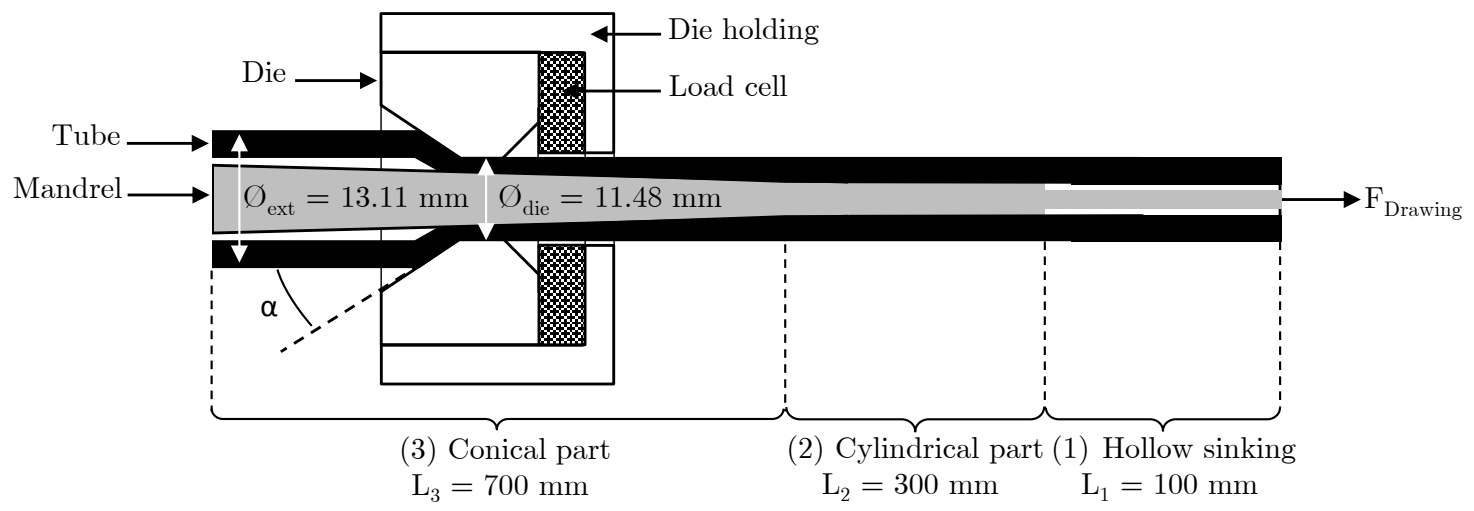

Figure 1: Schematic representation of the conical mandrel drawing process (dimensions were exaggerated in the figure for clarity)

\begin{tabular}{|l|c|c|c|c|}
\hline & \multirow{2}{*}{ Part (1) } & \multirow{2}{*}{ Part (2) } & \multicolumn{2}{|c|}{ Part (3): conical zone } \\
& & & $\emptyset_{\min }$ & $\emptyset_{\max }$ \\
\hline Nominal diameter (mm) & 8.7 & 9.0 & 9.0 & 10.3 \\
\hline Section reduction (\%) & 16.9 & 17.4 & 17.4 & 58.2 \\
\hline Thickness reduction(\%) & 0 & 0.8 & 0.8 & 52.8 \\
\hline Length of the part (mm) & 100 & 300 & \multicolumn{3}{|c|}{700} \\
\hline
\end{tabular}

Table 2: Nominal mandrel dimensions and expected section and thickness reductions

inserted between the die and the die holding system (fig.1). A motion transducer was linked to the tube gripper. The whole drawing test was recorded with a high speed camera pointing at the exit of the die in order to locate the fracture locus. The drawing tests were carried out in the same lubricant conditions and the same drawing speed as the industrial process.

\subsection{Details on the tube and tools}

The material used in the study is a cobalt-chromium alloy L605 (ASTM F90). It is widely used in the biomedical industry due to its good corrosion and wear resistance. The composition of the alloy is detailed in the table 3 .

The mandrel and die are made of hardened steel and tungsten carbide (WC), respectively. The conical mandrels used in the experiments were machined from straight mandrels. The total mandrel length was $1000 \mathrm{~mm}$ and the conical part was $700 \mathrm{~mm}$ long. Consequently the mandrel semi-cone angle was very small i.e. $0.053^{\circ}$. Bui et al. (2011) and Bihamta et al. (2012) used a conical mandrel of shorter length $(84.18 \mathrm{~mm})$ and a diameter ranging from $39.34 \mathrm{~mm}$ to $49.39 \mathrm{~mm}$ and a semi-cone angle of $5^{\circ}$. Thus concerning the mandrel of this study, the machining was very difficult mainly due to the mandrel length and the cone angle. Real mandrels dimensions were

\begin{tabular}{lccccccccc}
\hline Co & $\mathrm{Cr}$ & $\mathrm{W}$ & $\mathrm{Ni}$ & $\mathrm{Fe}$ & $\mathrm{Mn}$ & $\mathrm{C}$ & $\mathrm{Si}$ & $\mathrm{P}$ & $\mathrm{S}$ \\
\hline balance & $19-21$ & $14-16$ & $9-11$ & $<3$ & $1-2$ & $0.05-0.015$ & $<1$ & $<0.04$ & $<0.03$
\end{tabular}

Table 3: L605 chemical composition per ASTM F90 (wt.\%) 


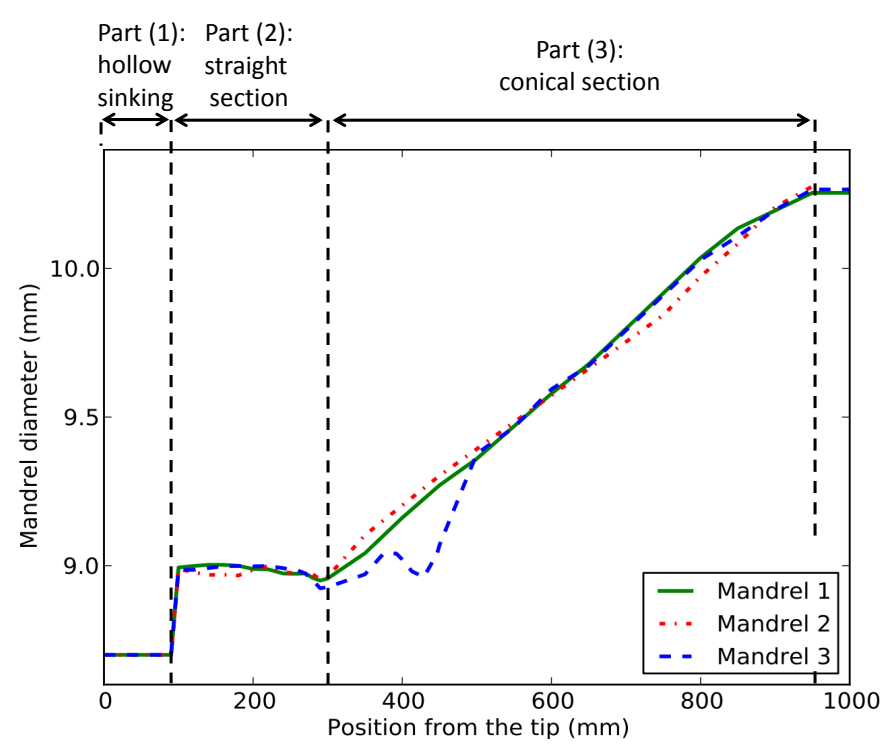

Figure 2: Evolution of the measured diameter along the conical mandrel

\begin{tabular}{|l|c|c|c|}
\hline Mandrel number & 1 & 2 & 3 \\
\hline Tube inner diameter $(\mathrm{mm})$ & 10.51 & 10.50 & 10.54 \\
\hline Tube outer diameter $(\mathrm{mm})$ & 13.11 & 13.11 & 13.11 \\
\hline Initial mean section $\left(\mathrm{mm}^{2}\right)$ & 48.26 & 48.39 & 47.05 \\
\hline
\end{tabular}

Table 4: Initial tube dimensions used with the corresponding mandrel

measured with a laser measurement system. The measured geometries of the three mandrels that were used are represented in figure 2 . The precise initial tube dimensions and sections are detailed in the table 4 .

\section{Results of the drawing tests}

\subsection{Drawing Force measurements}

Figure 3 shows the drawing force and mandrel diameter at the die location versus mandrel displacement obtained during the three conical mandrel drawing tests. A clear link appears between the drawing force and the mandrel diameter. For example the mandrel 3 shows diameter variations due to difficulties during machining, consequently, as shown in figure 3(c) the drawing force fluctuates according to the mandrel diameter variations.

Figure 4 summarizes the three drawing forces for the three tests. The forces are plotted as function of the mandrel displacement in figure 4(a) and as function of the section reduction in figure 4(b). This latter highlights the good repeatability of the tests as the three curves corresponding to the three drawing tests are very close.

\subsection{Tube dimensions at fracture}

The displacement measurement related to the precise characterisation of the mandrel geometry enabled to know with very good accuracy the mandrel diameter at the die location at any time. 


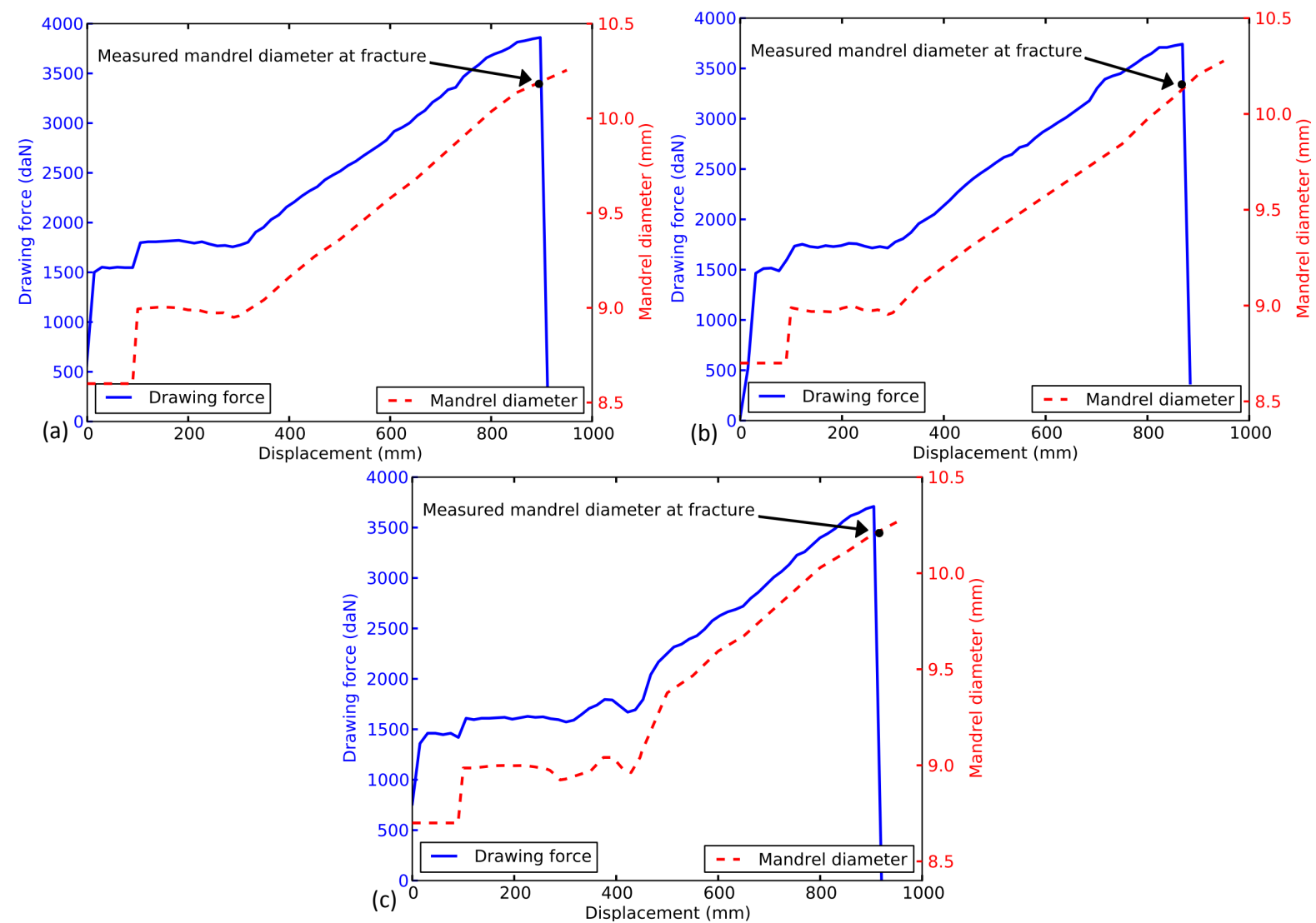

Figure 3: Drawing force and mandrel diameter versus displacement obtained for a conical mandrel drawing test: (a) mandrel 1, (b) mandrel 2, (c) mandrel 3.
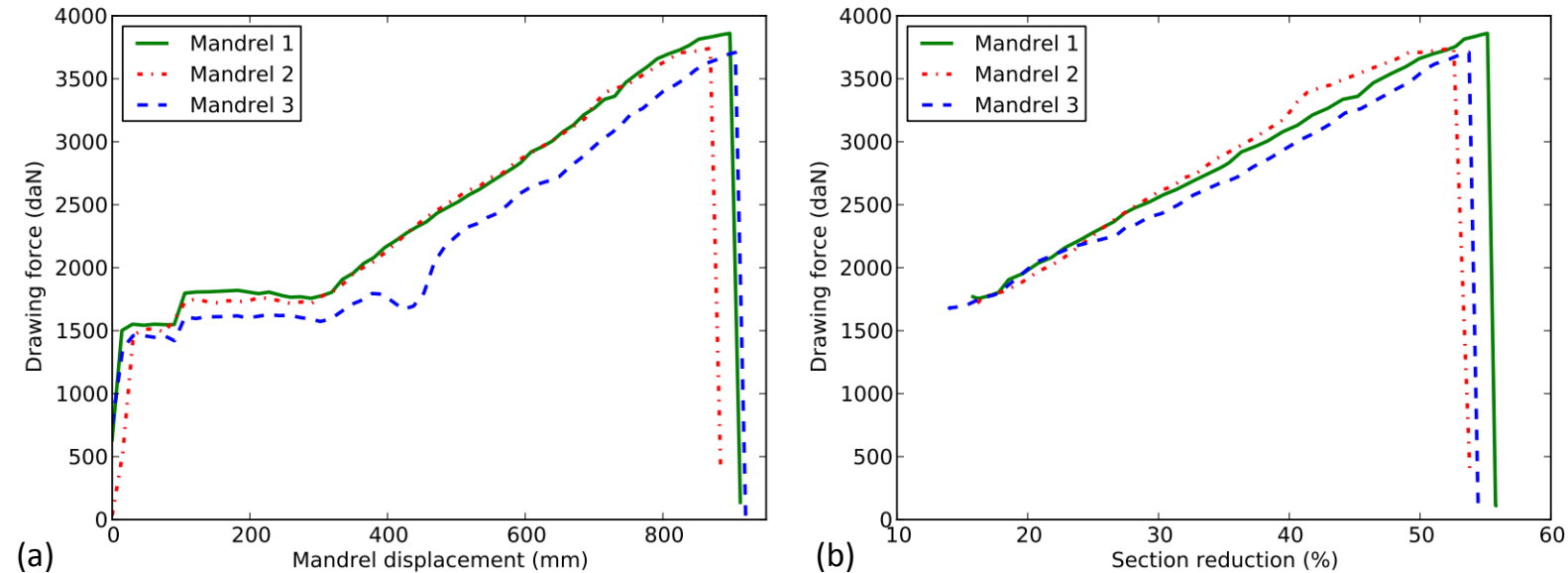

Figure 4: (a) Force versus mandrel displacement and (b) force versus section reduction during the conical mandrel drawings. 


\begin{tabular}{|l|c|c|c|}
\hline Mandrel number & 1 & 2 & 3 \\
\hline Section reduction at fracture (\%) & 54.17 & 53.37 & 53.91 \\
\hline Thickness reduction at fracture (\%) & 50.01 & 48.86 & 50.43 \\
\hline Maximum drawing Force (daN) & 3861 & 3741 & 3710 \\
\hline
\end{tabular}

Table 5: Maximum drawing force and corresponding section and thickness reduction at failure

Tube inner diameter was taken equal to the mandrel diameter. The tube outer diameter was considered equal to the die diameter. Then, it was possible to compute tube section at any time. The section reduction and force at fracture are presented table 5 .

\subsection{Fracture surface aspect of the tubes}

The general surface aspect of the tube reveals a surface that gets shinier with increasing section reduction. Tube roughness decreases with increasing imposed deformation. Photographies of the fractured tubes are presented in figure 5(a.1,b.1,c.1). It can be seen that fracture angle in the tube wall is about $45^{\circ}$ to the drawing direction. The tube number 1 presented in fig.5(a.1) also shows a change in fracture surface orientation: fracture angle is unchanged but the normal to the surface alternatively points to the inside and to the outside of the tube. Scanning Electron Microscopy (SEM) was performed on the tube fracture surface. Fractographies of the tubes reveal many cavities in the fracture surfaces which is characteristic of a dimple like fracture. Some voids nucleated on inclusion of brittle phase (carbide) which is dispersed in the matrix. Carbides particles can be observed in white in figure 5(b.4) which was taken with backscattered electron (BSE). Then the voids expanded and coalesced before causing full fracture.

Fractographies of the tubes reveal the fracture propagation direction. It can be seen from figure 5 (b.3,b.4) that there is a vertical scratch i.e. from the bottom to the top of the picture. The bottom and the top correspond to the inside and the outside of the tube respectively. More specifically in figure 5(b.4) it can be observed that all cavities are filled with a carbide except the cavity in the continuation of the scratch. The scratch starts from a cavity where the precipitate was initially. It indicates that the precipitate was extracted from its cavity and dragged along the surface from the bottom to the top of the picture and created a vertical scratch. So, considering SEM micrography, fracture initiated on the inner surface of the tube and propagated outward.

The scratch type morphology also indicates a shear fracture. Li et al. (2011) observed such a morphology on fractographies of shear-induced tensile test.

\section{Analysis of the results}

\subsection{Determination of the stress and strain states by mean of FEM}

The experimental results only permit to determine macroscopic data, but failure criteria calculation needs the local strain and stress fields to be evaluated. These fields can be evaluated by means of FEM (Palengat et al., 2013; Beland et al., 2011).

The FEM of the process was performed with ABAQUS/Explicit. Due to the geometry of the system, and considering that the mandrel, the die and the tube were perfectly coaxial, a simplification of the model was made considering an axisymmetric case. All the parts were modelled with 4-node linear solid elements CAX4R with reduced integration. A mass scaling option was used to speed up the computation. Figure 6 summarises the applied boundary conditions. The die 


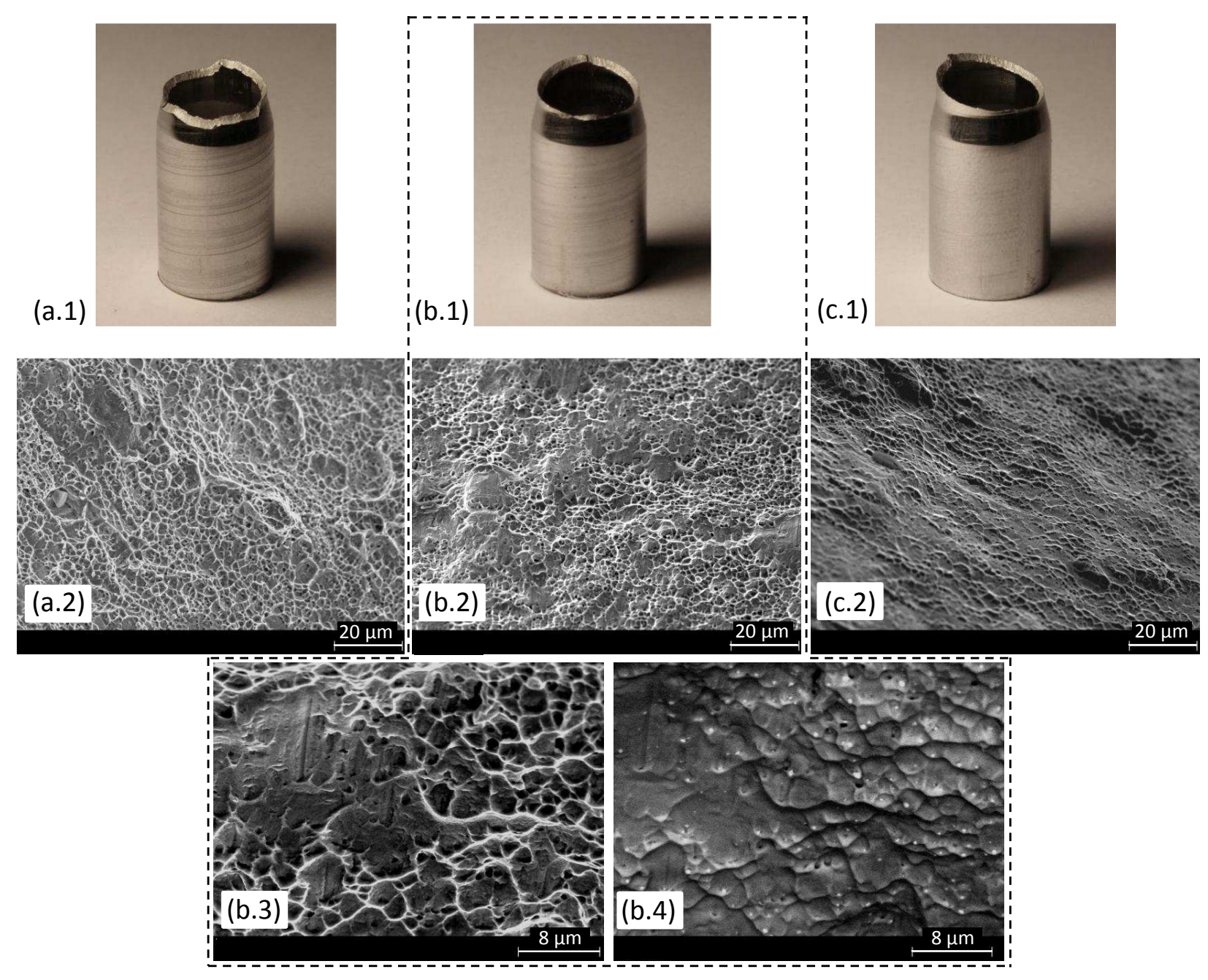

Figure 5: Fracture zone of drawn tubes (a.1,b.1,c.1), SEM fractography of tubes drawn on the three mandrels: (a.2, b.2, c.2) and (b.3) are topographic contrast pictures, (b.4) is a compositional contrast picture 


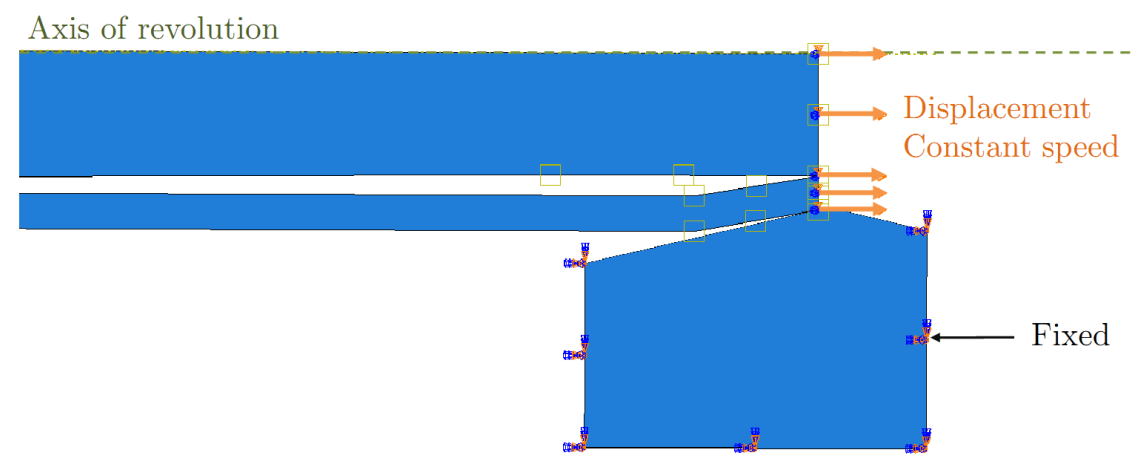

Figure 6: Boundary conditions applied to the tube and tools

was fixed and a displacement was applied to both mandrel and tube extremities. The displacement was imposed to reach a constant drawing speed. Some FEM inputs had to be characterised, i.e. material constitutive equations and frictional behaviour of the contacting materials.

\subsubsection{Material mechanical characterisation}

Tube tensile tests were carried out at room temperature on a $100 \mathrm{kN}$ hydraulic tensile testing machine. Tubular specimens were directly taken from the industrial process, in an annealed state. Specimens had an outer diameter of $11.5 \mathrm{~mm}$, a thickness of $1 \mathrm{~mm}$ and a gauge length of 100 $\mathrm{mm}$. Three series of tensile tests up to fracture were executed at two different strain rates (0.03 $\left.s^{-1}, 9 s^{-1}\right)$. The visco-plastic behaviour of the material shown on the flow curve in figure 7 can be described by a Johnson-Cook model. This semi-empirical model can describe the material behaviour taking into account the strain rate and the temperature effects. The flow stress according to Johnson-Cook model can be expressed as:

$$
\bar{\sigma}=\left(A+B \bar{\epsilon}_{p}^{n}\right)\left(1+C \ln \left(\frac{\dot{\overline{\epsilon_{p}}}}{\dot{\overline{\epsilon_{0}}}}\right)\right)\left(1-T^{* m}\right)
$$

with

$$
T^{*}=\left(\frac{T-T_{0}}{T_{m}-T_{0}}\right)
$$

with $\bar{\sigma}$ the material flow stress, $\bar{\epsilon}_{p}$ the equivalent plastic strain, $\dot{\overline{\epsilon_{p}}}$ the plastic strain rate, $\dot{\overline{\epsilon_{0}}}$ the reference plastic strain rate, $A$ the yield stress, $B$ the pre-exponential factor, $n$ the work-hardening coefficient, $C$ the strain rate sensitivity factor, $T$ is the temperature of the material, $T_{m}$ the melting temperature, $T_{0}$ the reference temperature and $m$ the thermal softening exponent.

Thermal measurements using a pyrometer have shown that the temperature increase during cold tube drawing does not exceed $100^{\circ} \mathrm{C}$ (Palengat et al., 2013). In this range of temperature, largely lower than the melting temperature, the dependence of the mechanical properties on temperature can be considered as negligible. Considering this slight increase, temperature effects will be neglected in the study. The Jonhson-Cook parameters fit on the experimental flow curve lead to the values listed in table 6 . 


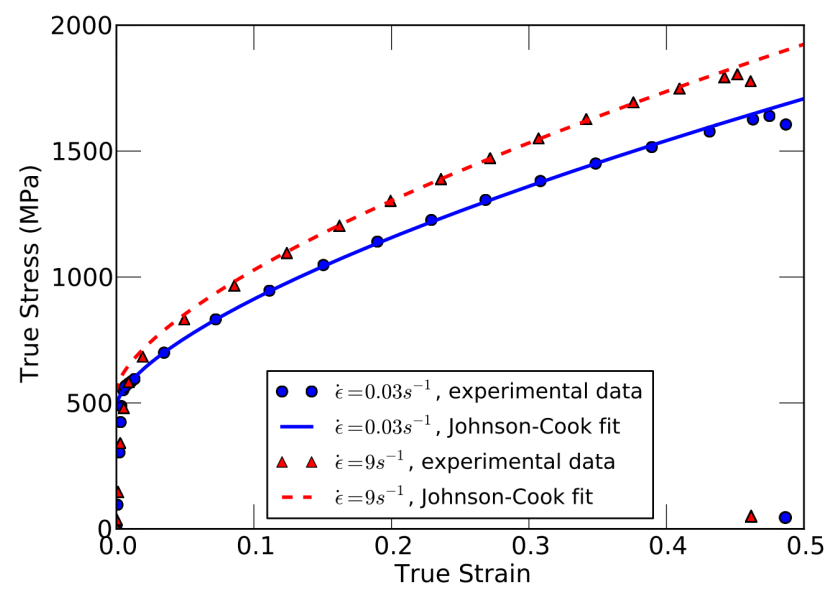

Figure 7: Parameters identification: superposition of the Johnson-Cook fit with the tensile tests conducted at different strain rates

\begin{tabular}{lcccc}
\hline $\mathrm{A}(\mathrm{MPa})$ & $\mathrm{B}(\mathrm{MPa})$ & $\mathrm{C}$ & $\mathrm{n}$ & $\dot{\overline{\epsilon_{0}}}$ \\
\hline 546 & 2216 & 0.0160 & 0.774 & 0.03 \\
\hline
\end{tabular}

Table 6: Fitted Johnson-Cook parameters for the L605 (ASTM F90)

\subsubsection{Identification of the friction coefficient}

Friction coefficient is dependent upon several parameters among which the most important are material roughness, relative velocity, thickness of the oil film and normal pressure (Szakaly and Lenard, 2010). The influence of these parameters on friction behaviour is not easily identifiable and measurable with specific tests.

In the FEM, the contact was supposed to behave following a Coulomb friction law:

$$
\tau=\mu p
$$

with $\tau$ the frictional shear stress, $\mu$ the friction coefficient and $p$ the normal stress in the contact surface.

There are several existing friction models in finite element codes. Petersen et al. (1997) compared the use of a constant friction coefficient and a pressure dependent one and found a better adequacy between experimental and numerical data with a pressure dependent friction coefficient. Ma et al. (2010) modelled the pressure dependency of the friction coefficient taking into account the evolution of the surface contact morphology with the pressure. They found that the friction coefficient decreases with increasing pressure. Azushima and Kudo (1995) defined intervals of pressure in which friction coefficient behaviour varies. They defined a low pressure interval ( $p<0.3 \sigma_{0}$, with $\sigma_{0}$ the yield stress) where the friction coefficient is constant, and a high pressure condition $\left(p>0.3 \sigma_{0}\right)$ where the friction coefficient decreases with increasing pressure. According to the referenced studies it is necessary to take into account the pressure dependence of the friction coefficient.

The development of specific tests to characterise the friction coefficient evolution regarding the contact pressure is a complex task. Thus, in this study, the friction coefficient values were determined by an inverse analysis. 


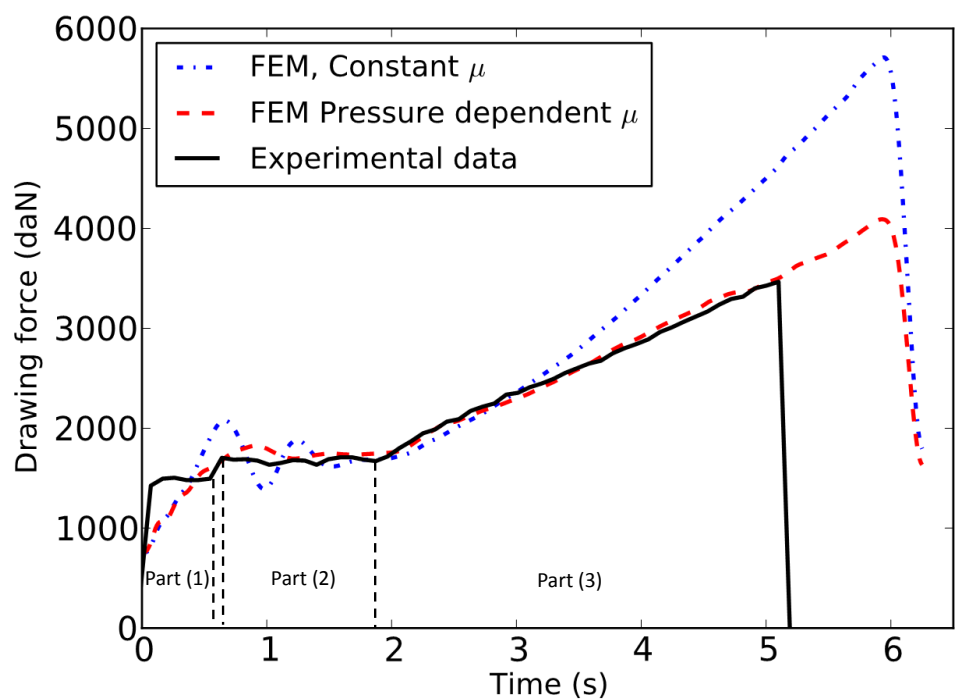

Figure 8: Comparison of the experimental and simulated drawing force for the conical mandrel drawing with constant and pressure dependent friction coefficients

Two friction coefficients have to be calibrated independently: the friction coefficient between the mandrel and the tube $\mu_{\text {mandrel/tube }}$ and the friction coefficient between the die and the tube $\mu_{\text {die/tube }}$. The identification of the two friction coefficients is done by means of the conical mandrel drawing test. The main principle of the inverse analysis is to simulate a drawing test with a value of friction coefficient such as numerical drawing force is equal to experimental one. The strategy was to first calibrate $\mu_{\text {die/tube }}$ using the hollow sinking step, part (1) in figure 1, then to calibrate $\mu_{\text {mandrel/tube }}$ using the constant diameter mandrel drawing step, part (2) in figure 1 . In a first time, two constant friction coefficients were identified. The set of identified friction coefficients was then used to simulate the full conical mandrel drawing considering the three mandrel parts as illustrated in figure 1. The comparison of the experimental and simulated drawing force in function of time is shown in figure 8. It can be observed from this figure that experimental and simulated drawing forces superimpose correctly for the mandrel parts (1) and (2). After these two parts, the simulated drawing force is over-estimated. This observation highlights the fact that constant friction coefficients are unable to model contact behaviour. As a consequence, the hypothesis of pressure dependent friction coefficients was formulated and two sets of pressure dependent friction coefficients were identified. Figure 9 presents the identified friction coefficients in function of the normal contact pressure. Finally, figure 8 shows the superimposition of the experimental and simulated drawing forces considering this case. It can be seen that the sets of identified pressure dependent friction coefficients enable to model the evolution of the drawing force accurately.

The need for a pressure dependent friction coefficient is reinforced by the analysis of the evolution of the contact stresses in the friction zones. Figure 10 shows the evolution of the normal contract stress, the shear contact stress and the friction coefficient in function of the position in the contact zone. Data are plotted for three different positions on the conical mandrel. Thus, the evolution of the above detailed stresses and friction coefficient is seen as function of the mandrel diameter. Figures 10(a-d) focus on the contact between the die and the tube while figures 10(e-h) concern the contact between the mandrel and the tube. Starting with the die/tube contact, it can be seen in figure 10(b) that normal contact stress in the tube varies along the contact and oscillates 


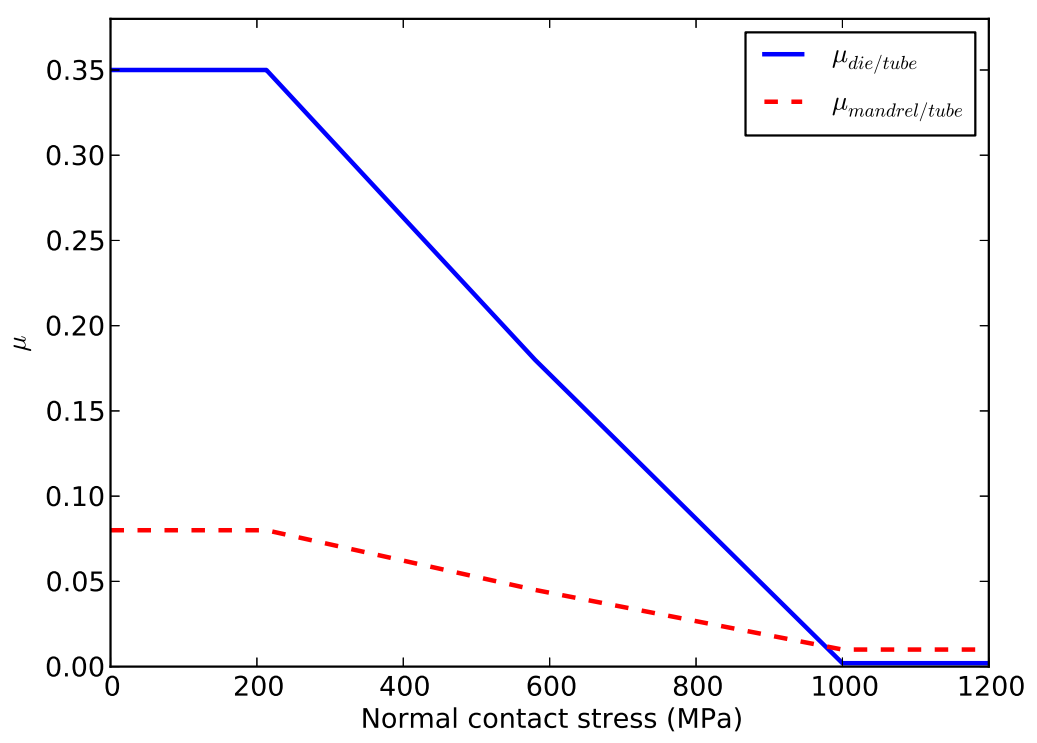

Figure 9: Dependence of the friction coefficients to the normal contact pressure

from 0 to $2200 \mathrm{MPa}$. Moreover, normal contract stress increases with increasing mandrel diameter. For a given mandrel diameter, normal contact stress shows a first peak at the die entrance, secondly stress tends to lower down and then shows a second higher peak corresponding to the end of the conical die part to finally end up at $0 \mathrm{MPa}$. Figure 10(c) shows irregular variations of the shear contact stress. Figure 10(d) presents the friction coefficient computed from the ratio of the shear (fig.10(c)) to normal (fig.10(b)) stress. It is seen from figure 10(d) that the friction coefficient varies locally along the contact and globally decreases with increasing mandrel diameter. Concerning the mandrel/tube contact (fig.10(f)), normal contact stress also varies along the contact and increases with increasing mandrel diameter. The shear contact stress $10(\mathrm{~g})$ shows little variations and as a consequence, the computed friction coefficient in figure $10(\mathrm{~g})$ is low. The above observations are in accordance with the experimental work on friction of Jeswiet (1998) and Kim et al. (2012).

\subsection{Comparative analysis of the failure criteria}

\subsubsection{Failure criteria calibration}

Tensile tests were both used to characterise the material behaviour and to calibrate the failure criteria. The choice of such a simple test to calibrate fracture criteria comes from the observation that this test is one of the most widely used in the industry. The objective of this study is also to evaluate the predictability quality of fracture criteria calibrated with tube tensile test only. More complex fracture criteria requiring other tests are not studied in this paper.

According to the stress state taking place in the tube tensile test, the expression of the damage or damage accumulation variable can be re-written as presented in the table 7 where $\sigma_{1}$ and $\epsilon_{1}$ are the tensile Cauchy stress and the logarithmic strain respectively. The critical computed values determined by means of tensile tests are also detailed. 

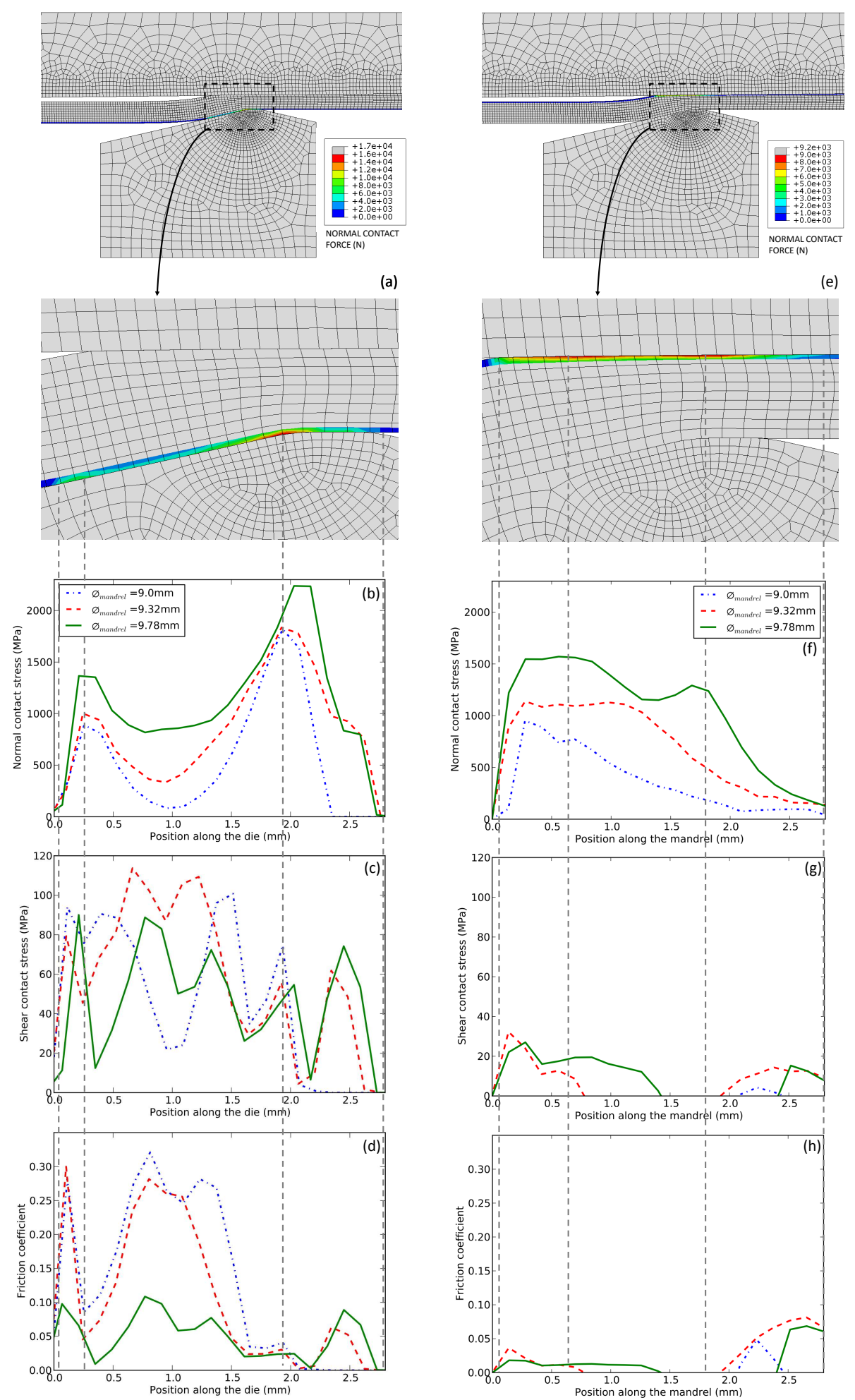

Figure 10: Evolution of the contact stresses and friction coefficients with the position along (a-d) the die and (e-h) the mandrel and depending on the mandrel diameter at the die location 


\begin{tabular}{lll}
\hline Abbreviation & Expression of the damage variable in tension & Critical Value \\
\hline STRN & $D_{1}=\epsilon_{1}$ & $D_{1}^{\text {crit }}=0.451$ \\
MSS & $D_{2}=\tau_{\max }=\frac{\sigma_{1}}{2}$ & $D_{2}^{\text {crit }}=902.6 \mathrm{MPa}$ \\
SHAB & $D_{3}=1$ & $D_{3}^{\text {crit }}=1$ \\
FREU & $D_{4}=\int_{0}^{\epsilon_{1}} \sigma_{1} d \epsilon_{1}$ & $D_{4}^{\text {crit }}=622.4 \mathrm{MPa}$ \\
COCK & $D_{5}=\int_{0}^{\epsilon_{1}} \max \left(0, \sigma_{1}\right) d \epsilon_{1}$ & $D_{5}^{\text {crit }}=622.4 \mathrm{MPa}$ \\
RICE & $D_{6}=\int_{0}^{\epsilon_{1}} \exp \left(\frac{1}{2}\right) d \epsilon_{1}$ & $D_{6}^{\text {crit }}=1.16$ \\
BROZ & $D_{7}=\int_{0}^{\epsilon_{1}} d \epsilon_{1}$ & $D_{7}^{\text {crit }}=0.701$ \\
ARGO & $D_{8}=\int_{0}^{\epsilon_{1}} \frac{4 \sigma_{1}}{3} d \epsilon_{1}$ & $D_{8}^{\text {crit }}=829.9 \mathrm{MPa}$ \\
OH & $D_{9}=\int_{0}^{\epsilon_{1}} d \epsilon_{1}$ & $D_{9}^{\text {crit }}=0.701$ \\
AYAD & $D_{10}=\int_{0}^{\epsilon_{1}} \frac{1}{3} d \epsilon_{1}$ & $D_{10}^{\text {crit }}=0.234$ \\
TREN & $D_{11}=\int_{0}^{\epsilon_{1}} \frac{\sigma_{1}}{2} d \epsilon_{1}$ & $D_{11}^{\text {crit }}=311.2 \mathrm{MPa}$ \\
\hline
\end{tabular}

Table 7: Details of the fracture criteria calibrated on a tube tensile test
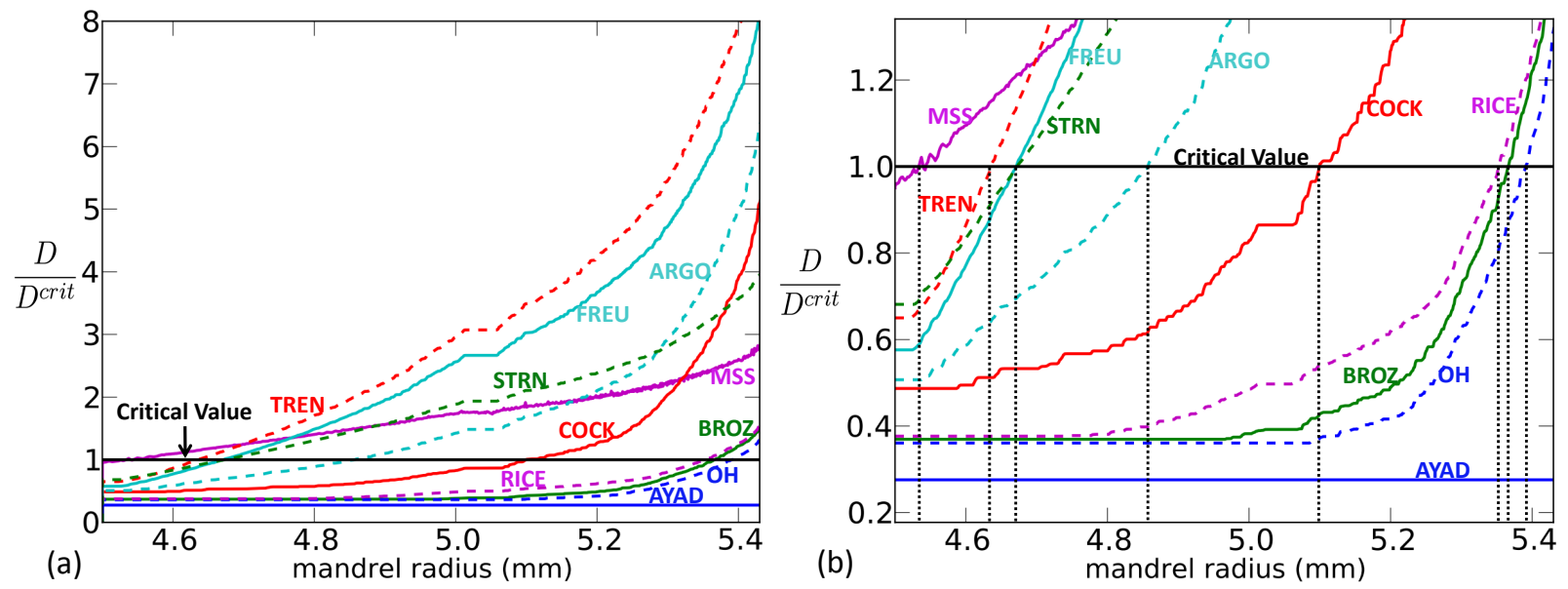

Figure 11: Evolution of failure criteria with mandrel radius, (a) global view, (b) zoom around the critical value and plot of the critical mandrel radii 


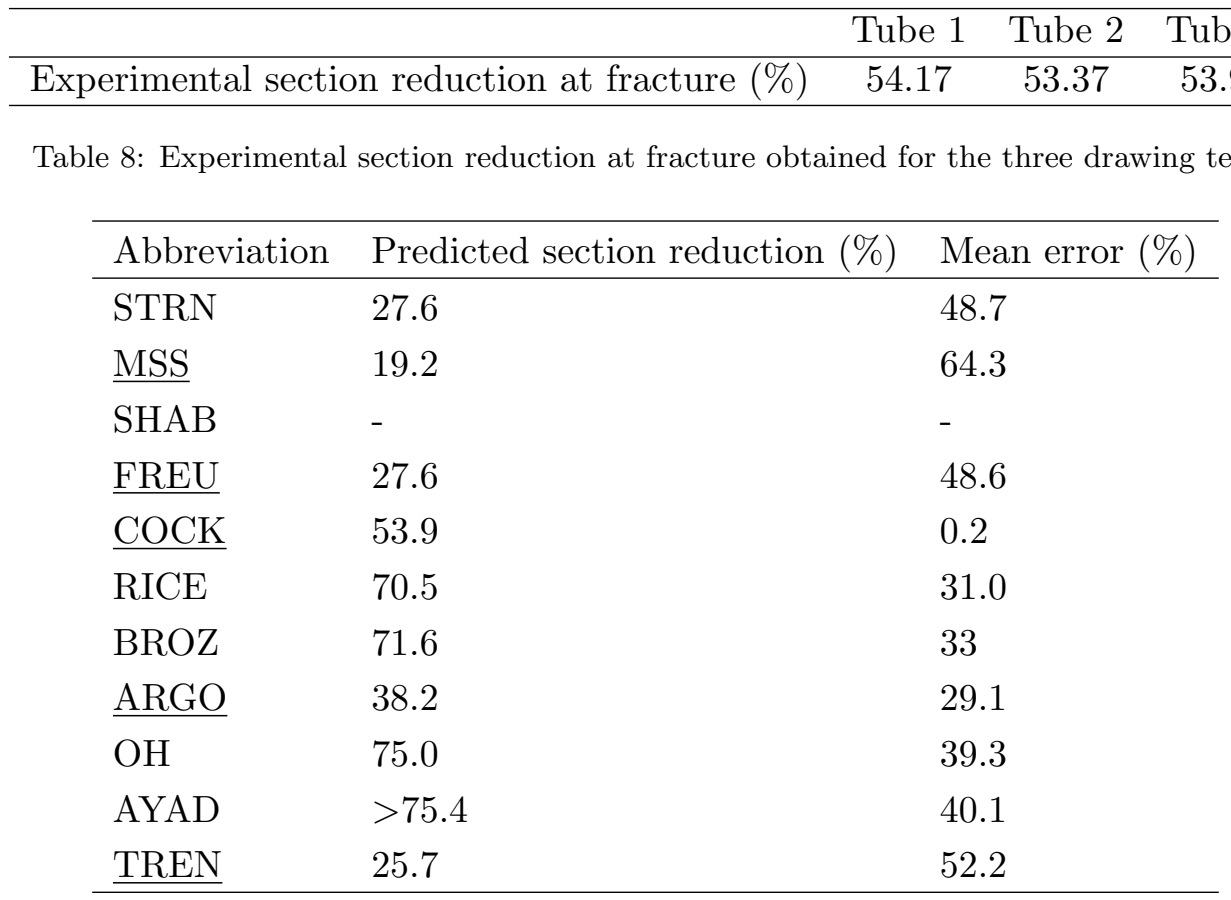

Table 9: Predicted section reduction and section reduction prediction error (underlined criteria are expressed in MPa, others are without units).

\subsubsection{Analysis of the failure criteria}

In the simulated drawing pass, the mandrel is considered having a perfect geometry, it has no dimensional variations due to machining. All damage variables were post-processed in order not to slow down the finite element computation. It was stated that failure would occur when the failure criterion was satisfied at a any single point in the tube. Figure 11 shows the increase of failure criteria with mandrel radius. Once a normalised damage variable crosses the horizontal black line (critical value of 1 ) the criterion is satisfied and the tube is supposed to fracture.

Table 8 lists the experimentally obtained section reduction at fracture for the three conical mandrel drawing tests. Table 9 shows the predicted section reduction for each failure criterion computed from the FEM. The mean error between experimental section reduction at failure and predicted one is also presented. It can be seen that estimation errors range from nearly $50 \%$ to 64.6\% for MSS, TREN, STRN and FREU. Estimation is improving with ARGO, RICE, OH and BROZ criteria, errors range from $28.5 \%$ to $40.5 \%$ but prediction is still not satisfactory. COCK criterion shows the lowest estimation error: $0.2 \%$. Maximum section reduction predicted by AYAD is unknown and above $75.4 \%$ because the simulation did not run long enough. This is due to an excessive mesh distortion that interrupted the simulation. To avoid this phenomenon remeshing techniques must be used. Finally SHAB criterion predicts failure at the very first step of tube drawing, thus, according to this criterion, drawing is not possible, which is obviously not the case.

Figure 12 presents ten tube inner surface profiles corresponding to ten failure criteria. Figure 12(a) first presents the position of the tube inner and outer surfaces relative to the die and the conical mandrel for the MSS criterion only. The drawing direction is also shown. In figure 12(b), the mandrel was removed for clarity and several tube inner surface profiles are superimposed. Each 

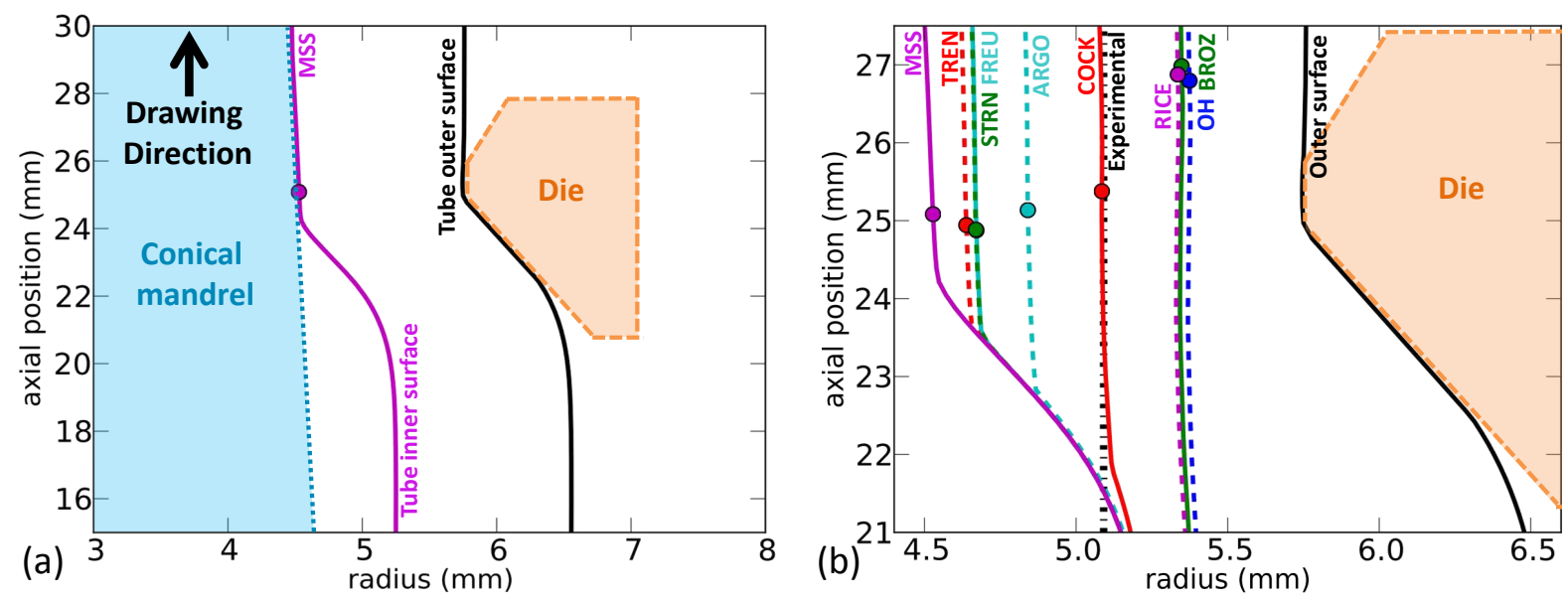

Figure 12: Failure initiation loci: (a) detail of the process, (b) enlargement of the zone close to the die and plot of the predicted tube inner surface and failure loccus for each criterion. The outer tube surface is common for all criteria.

inner tube surface is plotted for a given failure criterion and corresponds to the moment when the criterion is satisfied. The outer tube surface is common for all the failure criteria. The mean experimental tube inner radius is also plotted. Thus one can easily compare the maximum reduction predicted by each criterion. As mentioned earlier, COCK is very close to the experimental test, RICE, OH and BROZ are overestimating the maximum reduction while ARGO underestimates it. There are no data corresponding to AYAD criterion since the simulation did not run long enough but the predicted section reduction at fracture is overestimated. The tube inner surface would be located between $\mathrm{OH}$ prediction and the outer surface. Figure 12 also shows the point where failure criteria is verified for each criterion. This point represents the locus of failure initiation. It can be seen that all the failure initiation points are located at the tube inner surface. Fracture is then expected to initiate on the inner tube surface and to propagate outward. This observation is consistent with the failure propagation direction observed on SEM in figure 5. The variations of axial position is partly due the FEM mesh. Indeed, damage variables are computed at the nodes and the initial mesh is getting more distorted with increasing tube reduction.

Fracture locus is well predicted by nine of the eleven failure criteria but only COCK is able to quantitatively predict fracture. The reason why COCK seems to be the only failure criterion able to predict the onset of fracture is of two orders:

- First, damage variables are calibrated on uniaxial tensile tests where the major principal stress is the tensile stress and the other two are zero. While some of the damage variables are expressed in terms of hydrostatic stress or equivalent stress, such a calibration results in a great simplification of the damage variable expression. Thus some of them are made equivalent for the tensile test e.g. COCK and FREU or BROZ and $\mathrm{OH}$ (table 7). COCK gives good results as it is expressed in terms of the largest principal stress which is tensile both on calibration test and on tube drawing.

- Secondly, the state of stress reached during drawing is much more complex than simple uniaxial tensile test. Some damage variables are more able to take into account such a complex stress state (BROZ, ARGO, AYAD, RICE). The problem is that they are calibrated on sim- 


\begin{tabular}{lcccc}
\hline Die semi-cone angle $\left({ }^{\circ}\right)$ & 5 & 13.12 & 16 & 20 \\
\hline Experimental section reduction at fracture (\%) & $>56.4\left(^{*}\right)$ & 53.8 & 50.7 & 49.9 \\
Predicted section reduction at fracture (\%) & 59.7 & 53.9 & 51.4 & 47.1 \\
Error (\%) & - & 0.2 & 1.3 & 5.6 \\
\hline
\end{tabular}

Table 10: Experimental section reduction at fracture and Cockcroft-Latham predicted section reduction in function of the die semi-cone angle. $\left(^{*}\right)$ Section reduction at fracture was not identified because the tube did not break during the test.

pler mechanical tests. Zadpoor (2009) observed that failure criteria calibration depended upon the range of stress triaxiality of the test they were calibrated on. Consequently, more complex failure criteria might give better results provided that they are calibrated on tests with more complex state of stress.

\subsubsection{Validation of Cockcroft-Latham failure criterion}

Further conical mandrel drawing tests were performed in order to validate the predictability of Cockcroft-Latham failure criterion. Three series of complementary drawing tests were made with dies of different semi-cone angle: $\alpha=5^{\circ}, \alpha=16^{\circ}$, and $\alpha=20^{\circ}$. The drawing conditions were identical to the first series of tests. A change in die geometry induces strain-stress fields variations during drawing and modify the friction conditions. Table 10 lists the experimentally observed section reductions at fracture and the Cockcroft-Latham failure criterion prediction for the four die semi-cone angles.

It can be seen from these complementary tests and simulations that Cockcroft-Latham failure criterion is able to predict failure accurately for different die semi-cone angles. During the test made with a semi-cone angle of $\alpha=5^{\circ}$ the tube did not fracture. For this die semi-cone angle, the experimental section reduction at fracture is unknown but above $56.4 \%$.

Finally, the prediction accuracy of Cockcroft-Latham calibrated on tensile test is usable for industrial tube drawing applications. According to the large number of studies about failure criteria, this paper confirms that that failure criteria based on the maximum principal stress are more reliable in predicting fracture. Moreover, the integration of plastic deformation energy along the deformation path is a better approach compared to instantaneous path-independent parameters because metal working process are strain history dependent as concluded by Venugopal-Rao et al. (2003).

Furthermore it can be concluded from this series of drawing tests that the maximum section at fracture increases with decreasing die semi-cone angle. Thus, the use of smaller die angles should be considered in the tube drawing industry to improve formability.

\section{Conclusions}

The present study aimed at selecting a failure criterion to be used in the metal forming industry and more particularly the tube drawing process. For the purpose of easy handling for industrial applications it was chosen to use a tensile test for the calibration of the failure criteria. In this context, eleven failure criteria based on instantaneous damage variables and damage accumulation 
variables were compared. The experimental tube fracture that was observed during the conical mandrel drawing was compared with the one predicted by the FEM. The different failure criteria were evaluated and Cockcroft-Latham failure criterion was found to be the most accurate to predict tube fracture. The section reduction at fracture was predicted with an error ranging from $0.2 \%$ to $5.6 \%$. Moreover, this criterion enabled to capture the effect of die angle variation on formability. Indeed, it was experimentally observed that an increase in die semi-angle from $5^{\circ}$ to $20^{\circ}$ caused the formability limit to be reduced, from a section reduction greater than $56.4 \%$ to $49.9 \%$. Cockcroft and Latham failure criterion was able to capture this geometrical effect and predicted an earlier failure with greater die semi-angle. The maximum section reduction was predicted to be $47.1 \%$ with a $20^{\circ}$ die semi-angle while it was estimated to be $59.7 \%$ with a $5^{\circ}$ die semi-angle. In the end, the prediction accuracy of Cockcroft and Latham criterion when calibrated on tensile test is satisfactory and can be used in industrial applications. It appears to be a reliable tool to define the drawing passes. 


\section{References}

Argon, A., Im, J., and Safoglu, R. (1975). Cavity formation from inclusions in ductile fracture. Metallurgical and Materials Transactions A, 6, 825-837.

Ayada, M., Higashino, T., and Mori, K. (1984). Central bursting in extrusion of inhomogeneous materials. Proceedings of the First ICTP. Advanced Technology of Plasticity, 1, 553-558.

Azushima, A. and Kudo, H. (1995). Direct observation of contact behaviour to interpret the pressure dependence of the coefficient of friction in sheet metal forming. CIRP Annals - Manufacturing Technology, 44(1), 209 - 212.

Barenblatt, G. (1962). The mathematical theory of equilibrium cracks in brittle fracture. volume 7 of Advances in Applied Mechanics, pages 55 - 129. Elsevier.

Beland, J.-F., Fafard, M., Rahem, A., D'Amours, G. and Cote, T. (2011). Optimization on the cold drawing process of 6063 aluminium tubes. Applied Mathematical Modelling, 35, 5302 - 5313.

Bihamta, R., Bui, Q.H., Guillot, M., D’Amours, G., Rahem, A. and Fafard, M. (2012). Application of a new procedure for the optimization of variable thickness drawing of aluminium tubes. CIRP Journal of Manufacturing Science and Technology, 5(2), $142-150$.

Bridgman, P. W. (1952). Studies in Large Plastic Flow and Fracture with Special Emphasis on the Effects of Hydrostatic Pressure. McGraw-Hill, New York.

Brozzo, P., Deluca, B., and Rendina, R. (1972). A new method for the prediction of formability limits of metal sheets. In Proceedings of the Seventh Biennial Congress of International Deep Drawing Research Group, Amsterdam, Netherlands.

Bui, Q., Bihamta, R., Guillot, M., D'Amours, G., Rahem, A., and Fafard, M. (2011). Investigation of the formability limit of aluminium tubes drawn with variable wall thickness. Journal of Materials Processing Technology, 211(3), $402-414$.

Chaboche, J. (1988). Continuum damage mechanics: Part 1. general concepts. Journal of Applied Mechanics, 55(1), 59-72.

Cockcroft, M. G. and Latham, D. J. (1968). Ductility and the workability of metals. Journal of the Institute of Metals, 96, 33-39.

Fang, G., Ai, W.-J., Leeflang, S., Duszczyk, J. and Zhou, J. (2013). Multipass cold drawing of magnesium alloy minitubes for biodegradable vascular stents. Materials Science and Engineering: C , 33(6), $3481-3488$.

Freudenthal, A. M. (1950). The inelastic behavior of solids. Wiley, New York.

Gurson, A. (1977). Continuum theory of ductile rupture by void nucleation and growth: part i-yield criteria and flow rules for porous ductile media. ASME Transaction, Journal of Engineering Materials and Technology, 99, 2-17.

Hanada, K., Matsuzaki, K., Huang, X. and Chino, Y. (2013). Fabrication of Mg alloy tubes for biodegradable stent application. Materials Science and Engineering: C, http://dx.doi.org/10.1016/j.msec.2013.07.033

Jeswiet, J. (1998). A comparison of friction coefficients in cold rolling. Journal of Materials Processing Technology, $\mathbf{8 0 8 1}(0), 239-244$.

Kim, Y., Jain, M., and Metzger, D. (2012). Determination of pressure-dependent friction coefficient from draw-bend test and its application to cup drawing. International Journal of Machine Tools and Manufacture, 56(0), $69-78$.

Lee, W. B., Tai, W. H., and Tang, C. Y. (1997). Damage evolution and forming limit predictions of an a12024-t3 aluminium alloy. Journal of Materials Processing Technology, 63(1-3), 100-104.

Lemaitre, J. (1985). A continuous damage mechanics model for ductile fracture. Journal of Engineering Materials and Technology, 107(1), 83-89.

Li, H., Fu, M. W., Lu, J., and Yang, H. (2011). Ductile fracture: Experiments and computations. International Journal of Plasticity, 27(2), $147-180$.

Ma, X., de Rooij, M., and Schipper, D. (2010). A load dependent friction model for fully plastic contact conditions. Wear, 269(1112), $790-796$.

McClintock, F. A. (1968). A criterion for ductile fracture by the growth of holes. Journal of Applied Mechanics Trans. ASME, 35, 363-371.

Oh, S. I., Chen, C. C., and Kobayashi, S. (1976). Ductile fracture in axisymmetric extrusion and drawing, part ii, workability in extrusion and drawing. Journal of Engineering for Industry, 101, 33.

Oyane, M., Sato, T., Okimoto, K., and Shima, S. (1980). Criteria for ductile fracture and their applications. Journal of Mechanical Working Technology, 4, 65-81.

Palengat, M., Chagnon, G., Favier, D., Louche, H., Linardon, C., and Plaideau, C. (2013). Cold drawing of 3161 stainless steel thin-walled tubes: experiments and finite element analysis. International Journal of Mechanical Sciences, 70, 69-78

Petersen, S., Martins, P., and Bay, N. (1997). Friction in bulk metal forming: a general friction model vs. the law of constant friction. Journal of Materials Processing Technology, 66(13), 186 - 194. 
Poncin, P., Millet, C., Chevy, J., and Proft, J. (2004). Comparing and optimizing co-cr tubing sof stent applications. In Proceedings of the Materials and Processes for Medical Devices Conference.

Rice, J. R. and Tracey, D. M. (1969). A study of the void size effect based on the taylor dislocation model. Journal of the Mechanics and Physics of Solids, 17, 201-217.

Szakaly, E. D. and Lenard, J. G. (2010). The effect of process and material parameters on the coefficient of friction in the flat-die test. Journal of Materials Processing Technology, 210(67), 868 - 876.

Takuda, H., Mori, K., and Hatta, N. (1999). The application of some criteria for ductile fracture to the prediction of the forming limit of sheet metals. Journal of Materials Processing Technology, 95(13), 116 - 121.

Tang, C., Shen, W., and Lee, T. (1999). A damage-based criterion for fracture prediction in metal forming processes: a case study in al 2024t3 sheet. Journal of Materials Processing Technology, 8990(0), $79-83$.

Tvergaard, V. and Needleman, A. (1984). Analysis of the cup-cone fracture in a round tensile bar. Acta Metallurgica, 32(1), $157-169$.

Vallellano, C., Morales, D., and Garcia-Lomas, F. J. (2008). A study to predict failure in biaxially stretched sheets of aluminum alloy 2024-t3. Materials and Manufacturing Processes, 23(3), 303-310.

Venugopal-Rao, A., Ramakrishnan, N., and Krishna-Kumar, R. (2003). A comparative evaluation of the theoretical failure criteria for workability in cold forging. Journal of Materials Processing Technology, 142(1), 29 - 42.

Vujovic, V. and Shabaic, A. (1986). A new workability criterion for ductile metals. Journal of Engineering Materials and Technology, 108, 245-249.

Wu, P., Embury, J., Lloyd, D., Huang, Y., and Neale, K. (2009). Effects of superimposed hydrostatic pressure on sheet metal formability. International Journal of Plasticity, 25(9), 1711 - 1725.

Zadpoor, A. A., Sinke, J., and Benedictus, R. (2009). Formability prediction of high strength aluminum sheets. International Journal of Plasticity, 25(12), 2269 - 2297. 